\title{
Temporal Dynamics of Microcystins In Two Reservoirs With Different Trophic Status During The Early Growth Stage of Cyanobacteria
}

\section{Qingju Xue}

Nanjing Institute of Geography and Limnology https://orcid.org/0000-0001-6532-2017

\section{Ming Kong}

Nanjing Institute of Environmental Sciences

\section{Liqiang Xie}

Nanjing Institute of Geography and Limnology

\section{Tong Li}

Nanjing Institute of Geography and Limnology

\section{Mengna Liao}

Zhejiang Normal University

\section{Zebin Yan}

Zhejiang Normal University

\section{Yanyan Zhao ( $\nabla$ yyzhao@niglas.ac.cn )}

Nanjing Institute of Geography and Limnology

\section{Research Article}

Keywords: Intracellular, extracellular, Microcystin-YR, TN/TP ratio, mesotrophic reservoir, combined pollution

Posted Date: December 10th, 2021

DOI: https://doi.org/10.21203/rs.3.rs-1071653/v1

License: (c) (1) This work is licensed under a Creative Commons Attribution 4.0 International License. Read Full License 


\section{Abstract}

Harmful cyanobacterial blooms are increasing in frequency and severity, which makes their toxic secondary metabolites of microcystins (MCs) have been widely studied, especially in their distribution and influence factors in different habitats. However, the distribution of MCs on the early growth stage of harmful cyanobacteria and its influence factors and risks are still largely unknown. Thus, in the present study, two reservoirs (Lutian Reservoir and Lake Haitang) with different trophic status in China have been studied weekly from March to May in 2018, when the cyanobacteria communities were just in the early growth stage, to investigate the variation of MCs concentration and the relationships between MCs and environmental parameters. During the investigation, Lutian Reservoir and Lake Haitang were found to be mesotrophic and light eutrophic, respectively. In Lutian Reservoir, the concentration of EMCs was obviously higher than that of IMCs with a mean value of 0.323 and $0.264 \mu \mathrm{g} / \mathrm{L}$, respectively. Meanwhile, the concentration of EMCs also fluctuated more sharply than that of IMCs. Congeners of IMC-YR and EMC-LR were respectively dominant in total concentrations of IMCs and EMCs. Unsurprisingly, in Lake Haitang, the concentrations of IMC and EMC were both significantly higher than that in Lutian Reservoir with a mean concentration of 0.482 and $0.472 \mu \mathrm{g} / \mathrm{L}$, respectively. Differently, the concentration of MC-YR was dominant in both IMCs and EMCs, followed by MC-LR. In correlation analysis, the IMCs were significantly and positively correlated with the density and biomass of phytoplankton phyla and potential MCs-producing cyanobacteria and the parameters of water temperature (WT), nutrients and organic matters. Similar results were also observed for EMCs. While the different variation of MCs in two reservoirs might be primarily caused by the differences in WT, nutrients (especially phosphorus), organic matters and the composition of MCs-producing cyanobacteria. In addition, the coexistence of the dominant species of Pseudoanabaena sp., which can produce taste-and-odor compound of 2methylisoborneol (2-MIB), might have significant impacts on the concentration and toxicity of MCs. Our results suggested that the risks posed by MCs at the early growth stage of cyanobacteria should also deserve our attentions, especially in mesotrophic water bodies.

\section{Introduction}

Microcystins (MCs) are a family of potent hepatotoxins with nearly 300 congeners have been identified (Massey et al., 2020). They are secondary metabolites of certain genera of cyanobacteria, including Microcystis, Anabaena (Dolichospermum), Oscillatoria, Nostoc and Planktothrix, etc. (Buratti et al., 2017). Although the biological and ecological functions of MCs are still controversial, various studies have proved that it can protect the MC-producing algae from predators and oxidative stress, acting as allelochemicals, and promote the colony formation, etc. (Gan et al., 2012; Hu and Rzymski, 2019). In addition, MCs can also be transfered to other organisms of higher trophic levels through food chain (DíezQuijada et al., 2019). Due to its high toxicity, it can cause liver damage, promoting tumor, and affect reproduction (Chen et al., 2016; Huisman et al., 2018). What's worse, under the strong influences of both global climate change and anthropogenic activities, the increased MCs pollution has resulted in the occurrence of biological deaths of fish and mammals, even including humans. More recently, the deaths 
of more than 330 African elephants in Botswana were considered to be primarily caused by MCs ingestion (Wang et al., 2021). Thus, given the high toxicity and health threat, the dynamics and potential influence factors of MCs distribution in various water bodies around the world has become a current research hotspot.

To date, at least 108 countries, which distribute in all continents except Antarctica, have been detected the distribution of MCs (Benegas et al., 2021; Chaffin et al., 2018). MCs are primarily intracellular and released to the dissolved water when the cell lysis and death occurred (Rohrlack and Hyenstrand, 2007; Sivonen and Jones, 1999). So, the concentration of intracellular MCs is usually significantly higher than that of extracellular MCs. In a small, shallow and closed-basin lake in Ontario, Canada, the maximum concentration of intracellular MCs was above $4.2 \mathrm{mg} / \mathrm{L}$, while the concentration of extracellular MCs was extremely lower, but also exceeded $0.203 \mathrm{mg} / \mathrm{L}$ (Zastepa et al., 2014). The similar results were discovered in two freshwater bodies in China (Li et al., 2010; Zhang et al., 2018). In addition, MCs in one freshwater body usually consists of various MC congeners, and MC-LR and MC-RR are the dominant ones in most studies (Díez-Quijada et al., 2019; Tilahun et al., 2019). However, other MC congeners are also widely spread throughout the world and record relatively high concentrations in many lakes and reservoirs (Gurbuz et al., 2016; Simiyu et al., 2018). Therefore, further researches are needed to assess and prevent the risks caused by MCs pollution, and to better understand the mechanisms involved in the MCs production.

Due to the complicated interactions between various environmental variables and potential MCsproducing species, MCs in different water bodies usually exhibits obviously different variation characteristics. Several previous studies have found that the different composition of toxigenic genes played a dominant role in MCs production, congener composition and intracellular content (Okello et al., 2010a; Okello et al., 2010b; Shishido et al., 2019). Meanwhile, several studies suggested the rate of MCsproducing positively correlated with the growth rate of the cyanobacteria (Orr and Jones, 1998; Sivonen and Jones, 1999). The environmental parameters, which primarily refer to the physicochemical parameters of water bodies, also played an important role in MCs production (Xue et al., 2018). Among the various environmental parameters, water temperature is mainly positively correlated with MCs concentration (Walls et al., 2018), whereas the correlations between the nutrients and MCs varied from study to study (Wagner et al., 2021; Wang et al., 2018). In addition, the concentration of MCs can also be affected by other pollutants, such as antibiotics (Wan et al., 2021a), nanoplastics (Feng et al., 2020) and herbicides (Brêda-Alves et al., 2021). However, despite lots of studies have focused on this area, the mechanisms of how certain environmental parameters regulate the MCs production and variation are still poorly understood. What's more, most studies are concentrated in the results obtained during cyanobacterial blooms or monthly sampling, while few studies concerned on the early growth stage of cyanobacteria or higher frequency sampling.

Compared with natural lakes, reservoirs are characterized by larger fluctuations in water levels and more complex and variable hydrological conditions (Ford, 1990; Nowlin et al., 2004). Simultaneously, connections between reservoirs and human beings are more closely (Noori et al., 2018), and a slight 
water pollution may lead to a potentially high threat to human health. However, there are few researches focused on reservoirs. Thus, in the present study, two reservoirs (Lutian reservoir and Lake Haitang) with different trophic status were selected and sampled during the early growth period of cyanobacteria. Both the variations of three $M C$ congeners ( $M C-L R$, $-R R$, and $-Y R$ ) and the associated environmental parameters were investigated to (1) analyze the differences of physicochemical parameters and phytoplankton composition between the two reservoirs; (2) compare the temporal variation characteristics of three MC congeners in two reservoirs during the early growth stage of cyanobacteria; and (3) explore the potential driving factors that causing the different distribution patterns of MCs in two reservoirs.

\section{Materials And Methods Sites and sampling}

Lutian Reservoir and Lake Haitang are two typical reservoirs located in Jinhua City, Zhejiang Province, China (Fig. 1). Both reservoirs are small, and cover an area of 0.11 and $1.46 \mathrm{~km}^{2}$, respectively. Lutian Reservoir is located in the northern suburb of the city (Luodian County Shuanglong scenic area) at the altitude of $550 \sim 600 \mathrm{~m}\left(29.198^{\circ} \mathrm{N}, 119.630^{\circ} \mathrm{E}\right)$, which is about $20 \mathrm{~km}$ away from the downtown and rarely affected by human activities. As an important part of Shuanglong scenic spot, it provides the water source for the irrigation, aquaculture and recreation for surrounding citizens. While Lake Haitang $\left(29.056^{\circ}\right.$ $\mathrm{N}, 119.645^{\circ} \mathrm{E}$ ) is located in the downtown of Jinhua City, which attracts many citizens and tourists, with a lot of pollutants and interventions brought to it. Lake Haitang was built as core park green space of the city and was designed to have the function of driving the development of residential land, attracting commercial investment, and guiding residents of the leisure and entertainment. Due to the absolutely different functional positioning and pollution conditions, the two reservoirs are in different trophic states.

Two sites distributed in the center of two reservoirs were sampled weekly from March 11th to May 5th, 2018 (Fig. 1). All water samples were collected from the water surface (approximately at the depth of 0.5 $\mathrm{m}$ ) using a 2.5-L Plexiglas water sampler. The samples used for phytoplankton identification were preserved with $1 \%$ acidic Lugol's solution, other samples for physiochemical parameters $(0.5 \mathrm{~L})$ and MCs $(1 \mathrm{~L})$ analysis were all stored in a portable refrigerator $\left(0^{\circ} \mathrm{C}\right)$ and then transported to the laboratory. Water depth and Secchi disk depth (SD) was respectively measured by a sonar fathometer (SM-5A, Japan) and a Secchi disk in situ. Water temperature was measured using the water temperature meter equipped in the water sampler.

\section{Environmental parameters and MCs analysis}

Water samples were analyzed for chl-a, total nitrogen $(\mathrm{TN})$, ammonium $\left(\mathrm{NH}_{4}{ }^{+} \mathrm{N}\right)$, nitrate $\left(\mathrm{NO}_{3}{ }^{-} \mathrm{N}\right)$, total phosphorus (TP), orthophosphate $\left(\mathrm{PO}_{4}{ }^{3-}-\mathrm{P}\right)$, chemical oxygen demand (COD) and dissolved organic carbon (DOC), and all the analyzes were following the standard methods described in Jin and Tu (1990). Phytoplankton samples which preserved with $1 \%$ acidic Lugol's solution were concentrated to $50 \mathrm{~mL}$ after sedimentation for $48 \mathrm{~h}$. Then $0.1 \mathrm{~mL}$ concentrated samples were counted on a stereo microscope under $\times$ 
400 magnification after mixing. Phytoplankton species were identified and calculated according to Niu et al. (2011) and Xue et al. (2018).

Intracellular MCs (IMCs) and extracellular MCs (EMCs) were both analyzed, and the methods were according to the references of Su et al. (2015) and Xue et al. (2016), respectively. Briefly, after water sample filtration, the filter paper and filtrate were respectively used for IMCs and EMCs determination. Then, the filter paper was lyophilized and extracted. After the above treatments, the following procedures were nearly the same for IMCs and EMCs analysis. The supernatant and filtrate were both added to a preactivated HLB cartridge (200 mg, Oasis ${ }^{\circledR}$, Waters, Milford, MA, USA). After concentration, washing, elution, drying and redissolution, the concentrated samples were all analyzed by High-Performance Liquid Chromatography (HPLC, Agilent 1200 series, Palo Alto, CA, USA). The HPLC system was equipped with a DAD detector (Agilent, Palo Alto, CA, USA) and an ODS column (Agilent Eclipse XDB-C18, $5 \mu \mathrm{m}, 4.6 \mathrm{~mm} \times$ $150 \mathrm{~mm}$ ). Three dominant MC congeners (MC-LR, MC-RR and MC-YR) were analyzed for all the samples. Standards (three MC congeners) used for MCs analysis were bought from Sigma-Aldrich (München, Germany).

\section{Data analysis}

The correlation analysis between different variables was conducted with "correlation plot" app in OriginPro 2021b (version 9.8.5.204, OriginLab, Northampton, MA, USA) founded on the correlation type of "spearman", and the plot was also created by this app. One-way ANOVA and non-parametric tests were used to examine the difference of various variables between the two reservoirs, and these analyses were performed by IBM SPSS version 25 (USA). The Trophic Level Index (TLI) was calculated according to the method described in Jin et al. (1995), which based on the calculations of TLI(Chla), TLI(TP), TLI(TN), $\mathrm{TLI}(\mathrm{SD})$ and $\mathrm{TLI}\left(\mathrm{COD}_{\mathrm{Mn}}\right)$. In addition, the sum concentration of the three $\mathrm{MC}$ congeners was represented by total MC concentration (TIMCs and TEMCs) in the present study.

\section{Results}

\section{Physicochemical parameters variation}

During the survey, almost all the physicochemical parameters (except $\mathrm{NO}_{3}{ }^{-} \mathrm{N}$ ) exhibited significantly difference between the two reservoirs (Table 1). The water depth in Lutian Reservoir was significantly higher than that in Lake Haitang with higher values both detected in the late period of the survey. Although the sampling time and reservoir location were similar, the WT of Lutian Reservoir was significantly lower than that of Lake Haitang. And the WT of the two reservoirs both showed an increasing trend during the investigation.

Table 1. The mean values and ranges of various physicochemical parameters of the two reservoirs. 


\begin{tabular}{|c|c|c|c|c|}
\hline \multirow{2}{*}{ Parameters } & \multicolumn{2}{|c|}{ Lutian Reservoir } & \multicolumn{2}{|l|}{ Lake Haitang } \\
\hline & mean $\pm S D$ & range & mean $\pm S D$ & range \\
\hline Water Depth ${ }^{\star \star}(\mathrm{m})$ & $2.47 \pm 0.26$ & $2.25-3.09$ & $1.61 \pm 0.15$ & $1.44-1.80$ \\
\hline $\mathrm{SD}^{\star \star}(\mathrm{m})$ & $1.83 \pm 0.37$ & $1.10-2.35$ & $0.76 \pm 0.08$ & $0.65-0.86$ \\
\hline $\mathrm{WT}^{\star}\left({ }^{\circ} \mathrm{C}\right)$ & $15.07 \pm 3.38$ & $11.00-19.50$ & $19.36 \pm 3.27$ & $14.30-23.00$ \\
\hline $\mathrm{TN}^{\star \star}(\mathrm{mg} / \mathrm{LD}$ & $1.07 \pm 0.05$ & $0.97-1.16$ & $2.07 \pm 0.25$ & $1.76-2.44$ \\
\hline $\mathrm{NH}_{4}{ }^{+}-\mathrm{N}^{\star \star}(\mathrm{mg} / \mathrm{LQ}$ & $0.18 \pm 0.36$ & $0.01-1.12$ & $0.47 \pm 0.27$ & $0.26-1.12$ \\
\hline $\mathrm{NO}_{3}{ }^{-}-\mathrm{N}(\mathrm{mg} / \mathrm{LD}$ & $0.82 \pm 0.07$ & $0.70-0.93$ & $0.88 \pm 0.16$ & $0.71-1.18$ \\
\hline$T P^{* \star}$ (ug/LQ & $8.59 \pm 0.95$ & $7.06-10.23$ & $82.23 \pm 16.48$ & $54.51-101.10$ \\
\hline $\mathrm{PO}_{4}^{3--} \mathrm{P}^{*}(\mathrm{ug} / \mathrm{L} \rrbracket$ & $1.28 \pm 1.06$ & $0.16-3.76$ & $8.09 \pm 5.95$ & $1.28-17.94$ \\
\hline Chla ${ }^{\star \star}(\mathrm{ug} / \mathrm{L})$ & $2.78 \pm 1.03$ & $1.67-4.36$ & $52.45 \pm 24.69$ & $21.76-89.37$ \\
\hline $\mathrm{COD}_{\mathrm{Mn}}{ }^{* *}(\mathrm{mg} / \mathrm{L} \mathbb{V}$ & $1.57 \pm 0.23$ & $1.13-1.85$ & $4.32 \pm 0.80$ & $3.48-5.81$ \\
\hline $\mathrm{DOC}^{\star \star}(\mathrm{mg} / \mathrm{L})$ & $1.42 \pm 0.11$ & $1.32-1.67$ & $2.77 \pm 0.30$ & $2.42-3.21$ \\
\hline
\end{tabular}

* and $* *$ indicate a significant difference between the two reservoirs at $p<0.05$ and $p<0.01$, respectively.

The two reservoirs also exhibited significant differences in trophic state. The nutrient parameters of TN, $\mathrm{NH}_{4}{ }^{+}-\mathrm{N}, \mathrm{TP}$ and $\mathrm{PO}_{4}{ }^{3-}-\mathrm{P}$ in Lake Haitang were all significantly higher than that in Lutian Reservoir. In Lutian reservoir, the concentrations of $\mathrm{TN}, \mathrm{NH}_{4}{ }^{+}-\mathrm{N}$ and $\mathrm{NO}_{3}{ }^{-} \mathrm{N}$ all showed an increasing trend, while TP and $\mathrm{PO}_{4}{ }^{3-}-\mathrm{P}$ showed a downward tendency. However, in Lake Haitang, the concentrations of $\mathrm{TN}^{-} \mathrm{NO}_{3}{ }^{-} \mathrm{N}$ and TP showed a downward trend, whereas $\mathrm{NH}_{4}{ }^{+}-\mathrm{N}$ and $\mathrm{PO}_{4}{ }^{3-}-\mathrm{P}$ showed an increasing trend. The significant difference was also found in the concentration of chla with that in Lake Haitang and was nearly 20 times higher than that in Lutian Reservoir. In addition, the average TN/TP in Lutian Reservoir (125.23) was much higher and was nearly 5 folds of that in Lake Haitang Reservoir.

The organic pollution level in two reservoirs was both at a low level. Similarly, the concentration of $\operatorname{COD}_{\mathrm{Mn}}$ in Lutian Reservoir was much lower than that in Lake Haitang. The mean concentration of $\operatorname{COD}_{\mathrm{Mn}}$ in Lake Haitang was nearly 3 folds of that in Lutian Reservoir. And the $\mathrm{COD}_{M n}$ in two reservoirs were both increased in the early March and reached the peak value on 18th March. Similar to the dynamics of $\mathrm{COD}_{\mathrm{Mn}}$, the DOC also showed a downward trend and was significantly higher in Lake Haitang. The significant difference of the trophic state in two reservoirs was reflected by the different TLI values. TLI values of Lutian Reservoir ranged from 29.60 to 36.91 with a mean value of 32.25 , which mainly 
indicated mesotrophic level of Lutian Reservoir during the survey. However, TLI values of Lake Haitang ranged between 52.98 and 62.05 with a mean value of 57.45 , which represented light eutrophic of Lake Haitang.

\section{Phytoplankton composition}

The phytoplankton in both reservoirs consisted of eight phyla. The density of phytoplankton in Lutian Reservoir ranged from $1.36 \times 10^{5}$ to $1.19 \times 10^{6}$ ind./L with a mean value of $3.60 \times 10^{5}$ ind./L. And the maximum density was recorded on 30th March. As a whole, the density of phytoplankton in Lutian Reservoir exhibited a downward trend. Among the eight phyla, the bacillariophyta accounted for the highest proportion of $43.24 \%$, while chlorophyta and cyanophyta respectively accounted for the second and third highest proportion of $28.50 \%$ and $20.55 \%$ in Lutian Reservoir (Fig. 2). Significantly, the density of cyanobacteria in Lutian Reservoir accounted for the highest proportion on 30th March of $75.55 \%$. In Lake Haitang, the density of phytoplankton ranged from $1.81 \times 10^{7}$ to $6.12 \times 10^{7}$ ind./L with a mean value of $4.10 \times 10^{7}$ ind./L. The phytoplankton density sharply decreased in the early period and then increased to the maximum on 6th May. Different from Lutian Reservoir, the density of cyanophyta accounted for the highest proportion of $64.51 \%$ during the survey in Lake Haitang, followed by bacillariophyta and chlorophyta. Meanwhile, the proportion of cyanophyta accounted for the highest proportion during the whole investigation period except on the day of 30th March.

Variation of cyanobacteria density in both reservoirs was similar to that of the proportion of cyanobacteria in phytoplankton. Similarity, the density of cyanobacteria in both reservoirs exhibited extremely different variation trends. In Lutian Reservoir, the density of cyanobacteria ranged from $0.54 \times$ $10^{4}$ to $9.02 \times 10^{5}$ ind./L with a mean value of $1.37 \times 10^{5}$ ind./L. While the cyanobacteria density in Lake Haitang ranged from $6.34 \times 10^{6}$ to $5.03 \times 10^{7}$ ind./L with a mean value of $2.80 \times 10^{7}$ ind./L. The potential MC-producing algae in two reservoirs were mainly composed of Microcystis, Anabaena and Oscillatoria with the density of Anabaena accounted for the highest proportion during most of the time (Fig. 3). The density of Anabaena in Lake Haitang ranged from $4.63 \times 10^{6}$ to $3.67 \times 10^{7}$ ind./L with a mean value of $1.52 \times 10^{7}$ ind./L, while the density of Anabaena in Lutian reservoir was very low with a mean value of $9.35 \times 10^{4}$ ind./L. It's worth nothing that one species of cyanobacteria of Pseudoanabaena sp. was both identified in two reservoirs with a mean density of $1.05 \times 10^{4}$ in Lutian Reservoir and $6.58 \times 10^{6}$ ind./L in Lake Haitang.

\section{Microcystin dynamics}

The concentration of TIMCs in Lutian Reservoir changed gently and ranged from 0.228 to $0.33 \mu \mathrm{g} / \mathrm{L}$ with a mean value of $0.264 \mu \mathrm{g} / \mathrm{L}$ (Fig. 4a). The concentration of three MCs congeners of IMC-LR, IMC-RR and IMC-YR respectively accounted for $37.44 \%, 13.54 \%$ and $49.02 \%$ of the concentration of TIMCs. Among the three MC congeners, the concentration of IMC-YR dominated most of the time, while IMC-LR just dominated on 11th March, 21 st April and 29th April. The concentration of IMC-YR ranged from 0.069 to $0.192 \mu \mathrm{g} / \mathrm{L}$ with a mean value of $0.128 \mu \mathrm{g} / \mathrm{L}$. The variation pattern of IMC-LR was similar to that of 
TIMCs with the concentration ranged from 0.06 to $0.157 \mu \mathrm{g} / \mathrm{L}$ and a mean value of $0.10 \mu \mathrm{g} / \mathrm{L}$. The concentration of IMC-RR was extremely low during the survey with a mean value of $0.037 \mu \mathrm{g} / \mathrm{L}$.

Different from the variation of TIMCs, the concentration of TEMCs in Lutian Reservoir exhibited larger fluctuation (Fig. 4b). The concentration of TEMCs reached two peaks on 11th March and 14th April respectively with the value of 0.697 and $0.352 \mu \mathrm{g} / \mathrm{L}$. The mean concentration of TEMCs was $0.323 \mu \mathrm{g} / \mathrm{L}$, which was obviously higher than that of TIMCs. The dynamic of three extracellular MC congeners also varied significantly different from intracellular congeners. The mean proportions of EMC-LR, EMC-RR and EMC-YR were $49.80 \%, 14.60 \%$ and $35.60 \%$, respectively. The concentration of EMC-RR dominated in the first two sampling times, and EMC-LR dominated the next three times and the last time, while EMC-YR only dominated the rest three times. The concentrations of EMC-LR and EMC-YR ranged from 0.051 to $0.231 \mu \mathrm{g} / \mathrm{L}$ and from 0.022 to $0.191 \mu \mathrm{g} / \mathrm{L}$, respectively, with a mean value of 0.122 and $0.105 \mu \mathrm{g} / \mathrm{L}$. However, the EMC-RR only detected for three times, and the maximum concentration was $0.528 \mu \mathrm{g} / \mathrm{L}$, followed by 0.305 and $0.031 \mu \mathrm{g} / \mathrm{L}$.

Unsurprisingly, the concentration of TIMCs in Lake Haitang was significantly higher than that in Lutian Reservoir $(p<0.01$ ), with the concentration ranged from 0.331 to $0.746 \mu \mathrm{g} / \mathrm{L}$ and a mean value of 0.482 $\mu \mathrm{g} / \mathrm{L}$ (Fig. 4c). The concentration of TIMCs was extremely higher on 11th March and 6th April with a mean value of $0.737 \mu \mathrm{g} / \mathrm{L}$ and varied gently in the other sampling times. Compared to Lutian Reservoir, MC-YR was more dominant in Lake Haitang and accounted for the highest proportion during the survey except on 11th March. Concentrations of IMC-LR, IMC-RR and IMC-YR respectively accounted for 33.49\%, $12.32 \%$ and $54.19 \%$ of the TIMCs during the survey. The concentrations of IMC-LR, IMC-RR and IMC-YR ranged from 0.053 to $0.452 \mu \mathrm{g} / \mathrm{L}$, from 0 to $0.143 \mu \mathrm{g} / \mathrm{L}$, and from 0.134 to $0.495 \mu \mathrm{g} / \mathrm{L}$, respectively, with a mean value of $0.17,0.062$, and $0.25 \mu \mathrm{g} / \mathrm{L}$. The IMC-LR recorded the maximum on 11th March and sharply decreased in the other times, but it exhibited an increasing trend during the survey except the sampling on 11th March. The variation pattern of IMC-RR was similar to that of IMC-LR. Different from the above two congeners, the concentrations of IMC-YR exhibited obviously increasing trend and recorded the maximum on the last sampling.

The mean concentration of TEMCs in Lake Haitang was $0.472 \mu \mathrm{g} / \mathrm{L}$, which was a little lower than that of TIMCs, with the concentrations ranged from 0.311 to $0.649 \mu \mathrm{g} / \mathrm{L}$ and exhibited a downward trend (Fig. 4d). Similarly, the proportion of EMC-YR was the highest, and the concentrations of EMC-LR, EMC-RR and EMC-YR respectively accounted for $36.63 \%, 22.98 \%$ and $40.40 \%$ of the TEMCs. Concentrations of EMCLR, EMC-RR and EMC-YR ranged from 0 to $0.316 \mu \mathrm{g} / \mathrm{L}$, from 0.029 to $0.378 \mu \mathrm{g} / \mathrm{L}$, and 0.039 to 0.336 $\mu \mathrm{g} / \mathrm{L}$, respectively. And the mean values of EMC-LR, EMC-RR and EMC-YR were $0.176,0.109$, and 1.494 $\mu \mathrm{g} / \mathrm{L}$, respectively. Although extracellular and intracellular $\mathrm{MC}$ congeners had a similar variation trend, the concentrations of EMC-YR changed from increasing to a continuous decline after 15th April until the end of the survey.

\section{Correlation analysis}


In both reservoirs, the TIMCs and intracellular MC congeners were all positively and significantly correlated with most of the phytoplankton phyla and potential MC-producing species, including both of their density and biomass (Fig. 5). The positive correlations were also detected between extracellular MCs and phytoplankton phyla, but the number of significant correlations was much lesser. Similarly, intracellular MCs was also significantly correlated with more physicochemical parameters than extracellular MCs. The intracellular MCs positively and significantly correlated with $\mathrm{WT}, \mathrm{TN}, \mathrm{NH}_{4}{ }^{+}-\mathrm{N}, \mathrm{TP}$, $\mathrm{PO}_{4}{ }^{3-}-\mathrm{P}, \mathrm{COD}_{\mathrm{Mn}}$ and $\mathrm{DOC}$, while only negatively and significantly correlated with WD, SD and TN/TP. The similar results were also found in extracellular MCs. There were few significant correlations obtained between any pair of the MCs. In addition, significant correlations were also found between various phytoplankton phyla and physicochemical parameters.

In Lutian Reservoir, the significant correlations were relatively rare. The positive and significant correlations were only found between TIMCs and chlorophyta, IMC-YR and Microcystis, and TEMCs (EMCRR) and chla, while the negative and significant correlation were only found between IMC-LR and Pseudoanabaena sp., TIMCs and WD, EMC-LR and Cryptophyta, TEMCs (EMC-RR) and Pseudoanabaena sp., and EMC-LR and TN. However, in Lake Haitang, intracellular MCs and extracellular MCs were occasionally correlated with different variables that belong to the same class. Intracellular MCs was significantly correlated with Oscillatoria and $\mathrm{NO}_{3}{ }^{-} \mathrm{N}$, while extracellular MCs was significantly correlated with Microcystis and $\mathrm{NH}_{4}{ }^{+}-\mathrm{N}$. In addition, IMC-RR showed significantly correlated with $\mathrm{COD}_{\mathrm{Mn}}(\mathrm{r}=0.731)$ and DOC ( $r=0.802)$, and IMC-YR was significantly correlated with $\mathrm{NO}_{3}{ }^{-} \mathrm{N}(\mathrm{r}=-0.874)$, while EMC-RR was significantly correlated with $\mathrm{DOC}(\mathrm{r}=0.786)$, and EMC-YR was significantly correlated with $\mathrm{PO}_{4}{ }^{3-}-\mathrm{P}$ $(r=0.711)$ and $\operatorname{COD}_{\mathrm{Mn}}(\mathrm{r}=-0.833)$.

\section{Discussion}

In recent decades, MCs are increasing in detection frequency and severity with the global expansion of cyanobacterial blooms (Harke et al., 2016; Huisman et al., 2018). Previous studies indicated that MCs usually exhibits very different distribution characteristics in different water bodies due to the diversity of congener composition and the complexity of toxigenic mechanism (Khomutovska et al., 2020; Tilahun et al., 2019; Wood et al., 2006). In certain freshwater habitats, the concentration of MCs can reach extremely high levels. For instance, MCs in southern part of Africa reached a concentration of $124 \mathrm{mg} / \mathrm{L}$, and the contents of MCs reached $7300 \mu \mathrm{g} / \mathrm{g}$ dry weight (dw) in a fish pond in Wuhan, China and $7100 \mu \mathrm{g} / \mathrm{g} \mathrm{dw}$ in Portugal (Vasconcelos et al., 1996; Wang et al., 2021; Zhang et al., 1991). In the present study, the concentrations of total intracellular and extracellular MCs in two reservoirs were both below $1 \mu \mathrm{g} / \mathrm{L}$, which were similar to the results of several other water bodies also located in subtropical areas (Cunha et al., 2018; Wang et al., 2018; Zhang et al., 2018). Although MC concentrations showed great differences in different water bodies, the intracellular MCs concentration is usually higher than that of extracellular MCs (Zastepa et al., 2014; Zhang et al., 2018). On the contrary, the concentration of extracellular MCs in Lutian Reservoir was obviously higher than that of intracellular MCs in this study, which was consistent with the 
results of that on spring of Lake Chaohu in China (Shang et al., 2018). The conflicting results may be primarily related to the massive lysis of bloom or active release of intracellular MCs (Cordeiro-Araújo and Bittencourt-Oliveira, 2013; Díez-Quijada et al., 2019).

Due to the variability of molecular structure, MCs are usually recorded with multiple congeners coexistence in most water bodies (Graham et al., 2010). However, among the various MC congeners, MCLR and MC-RR usually dominated in most of the studies, while the dominance of MC-YR was relatively scarce (Major et al., 2018; Simiyu et al., 2018). In the present study, IMC-YR were dominant in both reservoirs, and EMC-LR and EMC-YR were respectively dominant in Lutian Reservoir and Lake Haitang. This was quite different from the results of several other lakes, even though they were almost locating in the same area. For example, in Poyang Lake, the most dominant MC congener in the whole year was MCRR, followed by MC-LR (Zhang et al., 2018), which was similarly to the results of Lake Taihu and Lake Yanghe (Wang et al., 2018). In addition, the dominate congener usually varied with time, as in many studies, MC-LR just dominant in a period and decreased its dominance or replaced by other congeners in other times (Tilahun et al., 2019; Xue et al., 2018; Xue et al., 2016). Nevertheless, although a lot of studies in natural freshwater ecosystems have focused on the relationships between various environmental factors and the composition of $\mathrm{MC}$ congeners, the exact regulating mechanisms are still in debate.

Among the various influencing factors, the characteristics of toxin-producing cyanobacteria species can directly affect the distribution of MCs (Wu et al., 2006). Different composition of MC-producing genera can not only lead to different concentrations but also congener compositions of MCs (Monchamp et al., 2014). In the current study, the dominant congener of IMC-YR was respectively correlated with the density of Microcystis and Oscillatoria in Lutian Reservoir and Lake Haitang, which might be one reason for the difference in MCs between the two reservoirs. Moreover, several previous studies have suggested that the growth rate of cyanobacteria cells is positively correlated with MCs production (Kaebernick et al., 2000; Orr and Jones, 1998). Thus, MCs can also reach a high concentration during the early growth period of cyanobacteria, but few studies have focused on this. Besides above biotic factors, programmed cell death, proportion of toxin-producing algae and colony formation are all reported correlating with MCs production (Harke et al., 2016; Hu and Rzymski, 2019; Wu et al., 2006). Meanwhile, the production of MCs also correlates with the existence of other aquatic organisms, and the concentrations of MCs usually be detected to significantly correlate with non-MC-producing species (Hu and Rzymski, 2019; Rzymski et al., 2020; Xue et al., 2018). Similarly, the concentrations of most congeners and total MCs in both reservoirs were significantly and positively correlated with the density of non-MC-producing algae.

The abiotic parameters of water temperature, nutrients, and turbidity are the main factors involved in various studies that can regulate MCs production (Harke et al., 2016; Xue et al., 2018). The elevated water temperature not only leads to the increase of cyanobacteria biomass but also the release of MCs (Walls et al., 2018). In the present study, water temperature was positively and significantly correlated with MCs concentration, which might be one of the reasons to explain the higher concentration in Lake Haitang. In contrast, water depth and SD were both negatively correlated with the concentration of MCs. The fluctuation of water depth can affect MCs through its influences on nutrient concentrations and water 
temperature, which can significantly influence the density of cyanobacteria (Bakker and Hilt, 2016). In addition, both water depth and SD can impact the structure of communities of aquatic organisms, such as zooplankton and aquatic plants(Bakker and Hilt, 2016; Jacoby et al., 2000), and thus the distribution of cyanobacteria and MCs production. The light condition in water column, which is closely related to water depth and SD, is also very important in MCs production (Harke et al., 2016).

Different forms of nutrients (except $\mathrm{NO}_{3}{ }^{-}-\mathrm{N}$ ) in the present study were all positively and significantly correlated with MCs concentration, while negatively correlation was only detected between the ratio of TN/TP and MCs concentration. Likewise, nutrient concentrations are positively correlated with MC concentrations in most other studies (Yuan and Pollard, 2017). However, the dynamic of MC may show a different trend when the nutrients are in limiting condition (Harke et al., 2016; Wagner et al., 2021; Xue et al., 2018). In addition, supported by several previous studies, nitrogen may have more significant effects on MCs production when compared with phosphorus (Downing et al., 2005; Harke and Gobler, 2013). Under nitrogen limited condition, the MC synthetic gene was downregulated and the content of MCs per cell was decreased. The $C O D_{M n}$ and $D O C$ were also found to positively correlated with MCs concentration in the present study. The value of $\mathrm{COD}_{\mathrm{Mn}}$ is usually used to indicate the levels of organic pollution, which was very important in the absorption of MCs on to suspended particles or sediment (Liu et al., 2019; Pang et al., 2021). Whereas DOC from different sources can affect cyanobacteria communities in different ways (Zhao et al., 2019). Although the above two parameters play an important role in the life history of cyanobacteria, there are still few relevant researches, especially on their effects on MCs production.

Recently, the coexistence of emerging contaminants and MCs in freshwater ecosystems has attracted more attention. Wan et al. (2021a) studied the effects of two antibiotics of moxifloxacin and gatifloxacin on $\mathrm{MC}$ release and found the appropriate concentration of fluoroquinolone antibiotics could increase $\mathrm{MC}$ release. Another contaminant of nanoplastics was also found to promote MC synthesis and release from Microcystis (Feng et al., 2020). The coexistence of MCs and other pollutants makes the biotoxicity more complex, with different concentrations exhibited different effects (Wan et al., 2021b). In the present study, IMC-YR and TIMCs were positively correlated with the density of Pseudoanabaena sp., which can produce taste-and-odor compound of 2-methylisoborneol (2-MIB) (Li et al., 2018), and different reservoirs and congeners exhibited different correlations. Although several studies have focused on the coexistence of MCs and taste-and-odor compounds (Graham et al., 2010; Shang et al., 2018), the interactions and toxicology between them are still unclear.

Summarily, during the early growth stage of cyanobacteria, the mean concentrations of intracellular and extracellular MCs were both in low levels $(<1 \mu \mathrm{g} / \mathrm{L})$ in two reservoirs, which suggested the risks of MCs posed to humans were also weak. However, several studies indicated the toxicity of MC-YR was similar to that of MC-LR (Gurbuz et al., 2016). Thus, the dominant of MC-YR in two reservoirs may also pose high potential risk to various organisms and humans, especially in Lutian Reservoir which was still in mesotrophic level and obtained little attention. Meanwhile, the fluctuation of MCs was sharp, monthly sampling in most studies certainly cannot assess the potential risk of MCs completely. Moreover, the 
coexistence of emerging contaminants and MCs should be paid more attention, especially the combined toxicity of them was largely unclear.

\section{Conclusion}

Although the concentrations of intracellular and extracellular MCs in both reservoirs were still below the value of the WHO drinking water guideline $(<1 \mu \mathrm{g} / \mathrm{L})$ during the early growth stage of cyanobacteria, the relatively high concentration of MCs and their associated risks in Lutian Reservoir may be overlooked. The concentration of MCs in two reservoirs both showed a sharply fluctuation, so the monthly sampling cannot completely assess their risks. In both reservoirs, the intracellular and extracellular MC congeners were all dominated by MC-YR most of the time, but its toxicity remains unclear. In addition, it was found that the concentration of extracellular MCs in both reservoirs was sometimes higher than that of intracellular MCs, which was contrary to the results of most studies, while the reasons for this are needed further studies.

The dynamic of MCs in two reservoirs were significantly and positively correlated with the density and biomass of phytoplankton phyla and potential MCs-producing cyanobacteria, $\mathrm{WT}, \mathrm{TN}, \mathrm{NH}_{4}{ }^{+} \mathrm{N}, \mathrm{TP}, \mathrm{PO}_{4}{ }^{3-}$ $P, C_{M n}$ and DOC, while were only negatively and significantly correlated with WD, SD and TN/TP. The differences of MCs between the two reservoirs might be primarily caused by the differences in WT, nutrients (especially phosphorus), organic matters and the composition of MCs-producing cyanobacteria. In addition, MCs in both reservoirs, especially in Lutian Reservoir, were significantly correlated with the density of Pseudoanabaena sp., which can produce taste-and-odor compound of 2-methylisoborneol (2MIB), might have significantly impacts on the concentration and toxicity of MCs.

\section{Declarations}

\section{Acknowledgments}

This research was supported by the National Natural Science Foundation of China (Grant No. 41907326, 41877486, 41877502), Natural Science Foundation of Jiangsu Province (Grant No. BK20170109) and the Youth Innovation Promotion Association CAS (2018352).

\section{Ethics approval and consent to participate}

Not applicable.

\section{Consent for publication}

Not applicable.

\section{Availability of data and materials}


The datasets used during the current study are available from the corresponding author on reasonable request.

\section{Competing interests}

The authors declare no competing interests.

\section{Authors' contributions}

Qingju Xue: formal analysis, writing, and original draft preparation. Ming Kong: sample analysis and manuscript review. Liqiang Xie: methodology and manuscript review. Tong Li, Mengna Liao and Zebin Yan: sample sampling, data acquisition and analysis. Yanyan Zhao: methodology, manuscript review and editing. All authors read and approved the final manuscript.

\section{References}

1. Bakker ES, Hilt S (2016) Impact of water-level fluctuations on cyanobacterial blooms: options for management. Aquat Ecol 50(3):485-498

2. Benegas GRS, Bernal SPF, de Oliveira VM, Passarini MRZ (2021) Antimicrobial activity against Microcystis aeruginosa and degradation of microcystin-LR by bacteria isolated from Antarctica. Environ Sci Pollut R 28:52381-52391

3. Brêda-Alves F, de Oliveira Fernandes V, Cordeiro-Araújo MK, Chia MA (2021) The combined effect of clethodim (herbicide) and nitrogen variation on allelopathic interactions between Microcystis aeruginosa and Raphidiopsis raciborskii. Environ Sci Pollut R 28:11528-11539

4. Buratti FM, Manganelli M, Vichi S, Stefanelli M, Scardala S, Testai E, Funari E (2017) Cyanotoxins: producing organisms, occurrence, toxicity, mechanism of action and human health toxicological risk evaluation. Arch Toxicol 91(3):1049-1130

5. Chaffin JD, Davis TW, Smith DJ, Baer MM, Dick GJ (2018) Interactions between nitrogen form, loading rate, and light intensity on Microcystis and Planktothrix growth and microcystin production. Harmful Algae 73:84-97

6. Chen L, Chen J, Zhang X, Xie P (2016) A review of reproductive toxicity of microcystins. J Hazard Mater 301:381-399

7. Cordeiro-Araújo MK, Bittencourt-Oliveira MdC (2013) Active release of microcystins controlled by an endogenous rhythm in the cyanobacterium Microcystis aeruginosa. Phycol Res 61(1):1-6

8. Cunha DGF, Dodds WK, Loiselle SA (2018) Factors related to water quality and thresholds for microcystin concentrations in subtropical Brazilian reservoirs. Inland Waters 8(3):368-380

9. Díez-Quijada L, Prieto Al, Guzmán-Guillén R, Jos A, Cameán AM (2019) Occurrence and toxicity of microcystin congeners other than MC-LR and MC-RR: A review. Food Chem Toxicol 125:106-132

10. Downing TG, Meyer C, Gehringer MM, van de Venter M (2005) Microcystin content of Microcystis aeruginosa is modulated by nitrogen uptake rate relative to specific growth rate or carbon fixation 
rate. Environ Toxicol 20(3):257-262

11. Feng L-J, Sun X-D, Zhu F-P, Feng Y, Duan J-L, Xiao F, Li X-Y, Shi Y, Wang Q, Sun J-W, Liu X-Y, Liu J-Q, Zhou L-L, Wang S-G, Ding Z, Tian H, Galloway TS, Yuan X-Z (2020) Nanoplastics promote microcystin synthesis and release from cyanobacterial Microcystis aeruginosa. Environ Sci Technol 54(6):3386-3394

12. Ford DE (1990) Reservoir transport processes. Reservoir Limnology: Ecological Perspectives. John Wiley \& Sons, New York

13. Gan N, Xiao Y, Zhu L, Wu Z, Liu J, Hu C, Song L (2012) The role of microcystins in maintaining colonies of bloom-forming Microcystis spp. Environ Microbiol 14(3):730-742

14. Graham JL, Loftin KA, Meyer MT, Ziegler AC (2010) Cyanotoxin mixtures and taste-and-odor compounds in cyanobacterial blooms from the midwestern United States. Environ Sci Technol 44(19):7361-7368

15. Gurbuz F, Uzunmehmetoğlu OY, Diler Ö, Metcalf JS, Codd GA (2016) Occurrence of microcystins in water, bloom, sediment and fish from a public water supply. Sci Total Environ 562:860-868

16. Harke MJ, Gobler CJ (2013) Global transcriptional responses of the toxic cyanobacterium, Microcystis aeruginosa, to nitrogen stress, phosphorus stress, and growth on organic matter.Plos One8(7), e69834

17. Harke MJ, Steffen MM, Gobler CJ, Otten TG, Wilhelm SW, Wood SA, Paerl HW (2016) A review of the global ecology, genomics, and biogeography of the toxic cyanobacterium, Microcystis spp. Harmful Algae 54:4-20

18. Hu C, Rzymski P (2019) Programmed cell death-like and accompanying release of microcystin in freshwater bloom-forming cyanobacterium Microcystis: From identification to ecological relevance. Toxins 11(12):706

19. Huisman J, Codd GA, Paerl HW, Ibelings BW, Verspagen JMH, Visser PM (2018) Cyanobacterial blooms. Nat Rev Microbiol 16(8):471-483

20. Jacoby JM, Collier DC, Welch EB, Hardy FJ, Crayton M (2000) Environmental factors associated with a toxic bloom of Microcystis aeruginosa. Can J Fish Aquat Sci 57(1):231-240

21. Jin X, Liu S, Zhang Z (1995) Lake environment in China. Oceanography press, Beijing

22. Jin X, Tu Q (1990) The standard methods for observation and analysis in lake eutrophication. Chinese Environmental Science Press, Beijing

23. Kaebernick M, Neilan BA, Börner T, Dittmann E (2000) Light and the transcriptional response of the microcystin biosynthesis gene cluster. Appl Environ Microb 66(8):3387-3392

24. Khomutovska N, Sandzewicz M, Łach $Ł$, Suska-Malawska M, Chmielewska M, Mazur-Marzec H, Cegłowska M, Niyatbekov T, Wood SA, Puddick J, Kwiatowski J, Jasser I (2020) Limited microcystin, anatoxin and cylindrospermopsin production by cyanobacteria from microbial mats in cold deserts. Toxins 12(4):244 
25. Li L, Zhu C, Xie C, Shao C, Yu S, Zhao L, Gao N (2018) Kinetics and mechanism of Pseudoanabaena cell inactivation, 2-MIB release and degradation under exposure of ozone, chlorine and permanganate. Water Res 147:422-428

26. Li Z, Yu J, Yang M, Zhang J, Burch MD, Han W (2010) Cyanobacterial population and harmful metabolites dynamics during a bloom in Yanghe Reservoir, North China. Harmful Algae 9(5):481488

27. Liu Y-L, Walker HW, Lenhart JJ (2019) The effect of natural organic matter on the adsorption of microcystin-LR onto clay minerals. Colloid Surface A 583:123964

28. Major Y, Kifle D, Spoof L, Meriluoto J (2018) Cyanobacteria and microcystins in Koka reservoir (Ethiopia). Environ Sci Pollut R 25(27):26861-26873

29. Massey IY, Al osman M, Yang F (2020) An overview on cyanobacterial blooms and toxins production: their occurrence and influencing factors. Toxin. Rev.,1-21

30. Monchamp M-E, Pick FR, Beisner BE, Maranger R (2014) Nitrogen Forms Influence Microcystin Concentration and Composition via Changes in Cyanobacterial Community Structure.Plos One9(1), e85573

31. Niu Y, Shen H, Chen J, Xie P, Yang X, Tao M, Ma Z, Qi M (2011) Phytoplankton community succession shaping bacterioplankton community composition in Lake Taihu, China. Water Res 45(14):41694182

32. Noori R, Berndtsson R, Adamowski F, Rabiee Abyaneh J, M (2018) Temporal and depth variation of water quality due to thermal stratification in Karkheh Reservoir. Iran J Hydrol-Reg Stud 19:279-286

33. Nowlin WH, Davies J-M, Nordin RN, Mazumder A (2004) Effects of water level fluctuation and shortterm climate variation on thermal and stratification regimes of a British Columbia reservoir and lake. Lake Reserv Manage 20(2):91-109

34. Okello W, Ostermaier V, Portmann C, Gademann K, Kurmayer R (2010a) Spatial isolation favours the divergence in microcystin net production by Microcystis in Ugandan freshwater lakes. Water Res 44(9):2803-2814

35. Okello W, Portmann C, Erhard M, Gademann K, Kurmayer R (2010b) Occurrence of microcystinproducing cyanobacteria in Ugandan freshwater habitats. Environ Toxicol 25(4):367-380

36. Orr PT, Jones GJ (1998) Relationship between microcystin production and cell division rates in nitrogen-limited Microcystis aeruginosa cultures. Limnol Oceanogr 43(7):1604-1614

37. Pang Z, Cai Y, Xiong W, Xiao J, Zou J (2021) A spectrophotometric method for measuring permanganate index $\left(\mathrm{COD}_{\mathrm{Mn}}\right)$ by N,N-diethyl-p-phenylenediamine (DPD). Chemosphere 266:128936

38. Rohrlack T, Hyenstrand P (2007) Fate of intracellular microcystins in the cyanobacterium Microcystis aeruginosa (Chroococcales, Cyanophyceae). Phycologia 46(3):277-283

39. Rzymski P, Klimaszyk P, Jurczak T, Poniedziałek B (2020) Oxidative stress, programmed cell death and microcystin release in Microcystis aeruginosa in response to Daphnia Grazers. Front. Microbiol. 11(1201) 
40. Shang L, Feng M, Xu X, Liu F, Ke F, Li W (2018) Co-Occurrence of microcystins and taste-and-odor compounds in drinking water source and their removal in a full-scale drinking water treatment plant. Toxins 10(1):26

41. Shishido TK, Jokela J, Humisto A, Suurnäkki S, Wahlsten M, Alvarenga DO, Sivonen K, Fewer DP (2019) The biosynthesis of rare homo-amino acid containing variants of microcystin by a benthic cyanobacterium. Mar Drugs 17(5):271

42. Simiyu BM, Oduor SO, Rohrlack T, Sitoki L, Kurmayer R (2018) Microcystin content in phytoplankton and in small fish from eutrophic Nyanza Gulf, Lake Victoria, Kenya. Toxins 10(7):275

43. Sivonen K, Jones G (1999) Cyanobacterial toxins, In: Toxic Cyanobacteria in Water: a Guide to Public Health Significance, Monitoring and Management. I. Chorus \& J. Bertram (Eds.). p. 41-91. The World Health Organization. ISBN 0-419-23930-8. E \& FN Spon, London, UK

44. Su X, Xue Q, Steinman A, Zhao Y, Xie L (2015) Spatiotemporal dynamics of microcystin variants and relationships with environmental parameters in Lake Taihu, China. Toxins 7(8):3224

45. Tilahun S, Kifle D, Zewde TW, Johansen JA, Demissie TB, Hansen JH (2019) Temporal dynamics of intra-and extra-cellular microcystins concentrations in Koka reservoir (Ethiopia): Implications for public health risk. Toxicon 168:83-92

46. Vasconcelos VM, Sivonen K, Evans WR, Carmichael WW, Namikoshi M (1996) Hepatotoxic microcystin diversity in cyanobacterial blooms collected in portuguese freshwaters. Water Res 30(10):2377-2384

47. Wagner ND, Quach E, Buscho S, Ricciardelli A, Kannan A, Naung SW, Phillip G, Sheppard B, Ferguson L, Allen A, Sharon C, Duke JR, Taylor RB, Austin BJ, Stovall JK, Haggard BE, Chambliss CK, Brooks BW, Scott JT (2021) Nitrogen form, concentration, and micronutrient availability affect microcystin production in cyanobacterial blooms. Harmful Algae 103:102002

48. Walls JT, Wyatt KH, Doll JC, Rubenstein EM, Rober AR (2018) Hot and toxic: Temperature regulates microcystin release from cyanobacteria. Sci Total Environ 610-611:786-795

49. Wan L, Wu Y, Zhang B, Yang W, Ding H, Zhang W (2021a) Effects of moxifloxacin and gatifloxacin stress on growth, photosynthesis, antioxidant responses, and microcystin release in Microcystis aeruginosa. J Hazard Mater 409:124518

50. Wan X, Cheng C, Gu Y, Shu X, Xie L, Zhao Y (2021b) Acute and chronic toxicity of microcystin-LR and phenanthrene alone or in combination to the cladoceran (Daphnia magna). Ecotox Environ Safe 220:112405

51. Wang H, Xu C, Liu Y, Jeppesen E, Svenning J-C, Wu J, Zhang W, Zhou T, Wang P, Nangombe S, Ma J, Duan H, Fang J, Xie P (2021) From unusual suspect to serial killer: Cyanotoxins boosted by climate change may jeopardize African megafauna. The Innovation, p 100092

52. Wang M, Shi W, Chen Q, Zhang J, Yi Q, Hu L (2018) Effects of nutrient temporal variations on toxic genotype and microcystin concentration in two eutrophic lakes. Ecotox Environ Safe 166:192-199

53. Wood SA, Holland PT, Stirling DJ, Briggs LR, Sprosen J, Ruck JG, Wear RG (2006) Survey of cyanotoxins in New Zealand water bodies between 2001 and 2004. New Zeal J Mar Fresh 
40(4):585-597

54. Wu SK, XIE P, LIANG GD, WANG SB, LIANG XM (2006) Relationships between microcystins and environmental parameters in 30 subtropical shallow lakes along the Yangtze River, China. Freshwater Biol 51(12):2309-2319

55. Xue Q, Rediske RR, Gong Z, Su X, Xu H, Cai Y, Zhao Y, Xie L (2018) Spatio-temporal variation of microcystins and its relationship to biotic and abiotic factors in Hongze Lake, China. J Great Lakes Res 44(2):253-262

56. Xue Q, Steinman AD, Su X, Zhao Y, Xie L (2016) Temporal dynamics of microcystins in Limnodrilus hoffmeisteri, a dominant oligochaete of hypereutrophic Lake Taihu, China. Environ Pollut 213:585593

57. Yuan LL, Pollard Al (2017) Using National-Scale Data To Develop Nutrient-microcystin relationships that guide management decisions. Environ Sci Technol 51(12):6972-6980

58. Zastepa A, Pick FR, Blais JM (2014) Fate and persistence of particulate and dissolved microcystinLA from Microcystis blooms. Hum Ecol Risk Assess 20(6):1670-1686

59. Zhang L, Liu J, Zhang D, Luo L, Liao Q, Yuan L, Wu N (2018) Seasonal and spatial variations of microcystins in Poyang Lake, the largest freshwater lake in China. Environ Sci Pollut R 25(7):63006307

60. Zhang Q-X, Yu M-J, Li S-H, Carmichael WW (1991) Cyclic peptide hepatotoxins from freshwater cyanobacterial (blue-green algae) waterblooms collected in Central China. Environ Toxicol Chem 10(3):313-321

61. Zhao M, Qu D, Shen W, Li M (2019) Effects of dissolved organic matter from different sources on Microcystis aeruginosa growth and physiological characteristics. Ecotox Environ Safe 176:125-131

\section{Figures}

\section{Figure 1}

Reservoirs and sampling sites locations.

\section{Figure 2}

Temporal variations of relative abundance of the phytoplankton in Lutian Reservoir (a) and Lake Haitang (b).

\section{Figure 3}


Dynamics of potential MC-producing algae density in Lutian Reservoir (a) and Lake Haitang (b).

\section{Figure 4}

Temporal variations of IMCs and EMCs in Lutian Reservoir (a, b) and Lake Haitang (c, d).

\section{Figure 5}

The correlation between various MCs and different environmental parameters in Lutian Reservoir and Lake Haitang. 